\title{
Princípios do uso de antimicrobianos: perguntas e respostas
}

\author{
Using antimicrobial drugs: questions and answers
}

\author{
Anna Sara S. Levin ${ }^{1}$, Cristina H. P. Kobata ${ }^{2}$, Marcelo N. Litvoc ${ }^{3}$
}

Levin ASS, Kobata CHP, Litvoc MN. Princípios do uso de antimicrobianos: perguntas e respostas / Using antimicrobial drugs: questions and answers. Rev Med (São Paulo). 2014 abr.-jun.;93(2):63-8.

RESUMO: Para indicar o uso de antimicrobianos é necessário ter à mente várias informações sobre as drogas, tais como espectro de atividade da droga, dados de farmacocinética e farmacodinâmica, como distribuição tecidual, plasmática e excreção, efeitos adversos e é necessário ter várias informações sobre o quadro clínico do paciente e o tipo de infecção e seu agente etiológico, tais como sítio de infecção e sensibilidade antimicrobiana. Não é possível abarcar todos estes aspectos em um artigo e optamos por abordar os princípios gerais do tratamento antimicrobiano por meio de perguntas e respostas. O objetivo é prover os conceitos básicos do uso de antimicrobianos. Apresentamos as principais classes de antimicrobianos e o seu espectro de ação, conceitos como infecção, colonização e contaminação, interpretação de culturas, indicações e duração de tratamento, vias de administração, associação de drogas, critérios de resposta ao tratamento, e profilaxia antimicrobiana.

DESCRITORES: Anti-infecciosos/uso terapêutico; Infecção/ prevenção \& controle; Antibioticoprofilaxia.

\begin{abstract}
In order to use antimicrobials well it is necessary to have information about the different drugs available, spectrum of activity, pharmacodynamic and pharmacokinetic data such as tissue distribution, excretion and plasma, adverse effects. It is also necessary to have information about the type and site of infection, its causative agent and antimicrobial susceptibility. We could not cover all these aspects in one article and we chose to approach the general principles of antimicrobial treatment using questions and answers. Our goal is to provide the basics for the use of antimicrobials. We present the main classes of antimicrobials and their spectrum, concepts such as infection, colonization and contamination, interpretation of cultures, indications and treatment duration, route of administration, drug combination, criteria to evaluate response to treatment, and antimicrobial prophylaxis.
\end{abstract}

KEYWORDS: Anti-infective agentes/therapeutic use; Infection/ prevention \& control; Antibiotic prophylaxis.

\footnotetext{
${ }^{1 .}$ Professora do Departamento de Moléstia Infecciosas e Parasitárias da Faculdade de Medicina as USP. E-mail: gcih.adm@hc.fm.usp.br.

2. Médica-Assistente do Serviço de Cirurgia Vascular do Hospital das Clínicas da FMUSP. E-mail: ckobata@uol.com.br.

3. Médico-Assistente da Divisão de Doenças Infecciosas e Parasitárias do Hospital das Clínicas da FMUSP. E-mail: malitvoc@uol.com.br.
} 
A ntimicrobianos foram descobertos em 1928 por Alexander Fleming quase por acaso. O pesquisador percebeu que havia uma contaminação de uma placa de cultura de Staphylococcus aureus por um fungo Penicillium notatum, e ao redor desta contaminação fúngica havia um halo de inibição de crescimento bacteriano. Assim, surgiu a ideia de que o fungo produzia uma substância que inibia o crescimento bacteriano e esta substância purificada foi denominada penicilina. Este achado foi publicado ${ }^{1}$. Fleming percebeu já no início, que havia a inibição de outras bactérias como pneumococos, estreptococos, gonococos e meningococos, porém era inútil contra: Mycobacterium tuberculosis e o agente da febre tifoide. Fleming, no entanto, nunca pensou na penicilina como agente terapêutico e ao longo do tempo abandonou o seu estudo.

Somente anos depois surgiu a ideia de que a penicilina pudesse ser utilizada para o tratamento de infecções bacterianas, avaliada por pesquisadores da Universidade de Oxford, Abraham, Chain e Florey, em $1940^{2}$ e $1941^{3}$. Fleming, impressionado com os bons resultados, convenceu o governo Britânico a produzi-la em larga escala para uso durante a II Guerra Mundial.

Desde o advento da penicilina, várias outras drogas antimicrobianas surgiram e com o seu uso surgiu a resistência microbiana.

Para se discutir o uso de antimicrobianos é necessário ter à mente várias informações sobre as drogas, tais como espectro de atividade da droga, dados de farmacocinética e farmacodinâmica como distribuição tecidual, plasmática e excreção, efeitos adversos e é necessário ter várias informações sobre o quadro clínico do paciente e o tipo de infecção e seu agente etiológico, tais como sítio de infecção e sensibilidade antimicrobiana.

Não seria possível abarcar todos estes aspectos em um artigo e optamos por abordar os princípios gerais do tratamento antimicrobiano por meio de perguntas e respostas.

\section{Qual são as principais classes e grupos de antimicrobianos?}

Os grandes grupos de antimicrobianos, apresentados de modo resumido, com alguns exemplos de drogas, são:

\section{Beta-lactâmicos}

> Penicilinas (penicilina, ampicilina, amoxicilina, oxacilina, ticarcilina, piperacilina)

$>$ Cefalosporinas (classificadas em gerações)

- Primeira (cefalotina, cefazolina, cefalexina, cefadroxil)

- Segunda (cefuroxima, cefoxitina)

- Terceira (ceftriaxona, cefotaxima)

- Terceira anti-pseudomonas (ceftazidima)

- Quarta (cefepima)

$>$ Carbapenens (imipenem, meropenem, ertapenem)

> Monobactâmicos (aztreonam)
Inibidores de beta-lactamase

$>$ Ácido clavulânico

$>$ Sulbactam

$>$ Tazobactam

$>$ Usados associados a:

- Ampicilina/amoxicilina (ac. clavulânico ou sulbactam)

- Ticarcilina (ac. clavulânico)

- Piperacilina (tazobactam)

Aminoglicosídeos

$>$ Gentamicina

$>$ Amicacina

$>$ Tobramicina

$>$ Neomicina

Macrolídeos

$>$ Eritromicina

$>$ Roxitromixina

$>$ Claritromicina

$>$ Azitromicina

\section{Quinolonas}

$>$ Ácido nalidíxico

$>$ Norfloxacina

$>$ Ciprofloxacina

$>$ Levofloxacina, moxifloxacina (também chamadas de quinolonas respiratórias)

Drogas com ação anti-anaeróbios

$>$ Metronidazol

$>$ Clindamicina

$>$ Cloranfenicol

Tetraciclinas e derivados

$>$ Tetraciclina

$>$ Doxiciclina

$>$ Minociclina

$>$ Tigeciclina

Glicopeptídeos

$>$ Vancomicina

$>$ Teicoplanina

Sulfas

$>$ Sulfametoxazol/trimetoprim

Sulfadiazina

Lipopetídeo

$>$ Daptomicina

Oxazolidinona

$>$ Linezolida

Polimixinas

> Polimixina B

> Polimixina E (também denominada colistina)

2. Qual é o espectro de atividade antimicrobiana das diferentes classes ou grupos de drogas?

Na Tabela 1, apresentamos um resumo do principal espectro de atividade dos antimicrobianos mais frequentemente prescritos. Nesta lista está descrita atividade apenas contra bactérias, porém há algumas drogas que têm alguma atividade anti-fúngica ou anti-parasitária. 
Rev Med (São Paulo). 2014 abr.-jun.;93(2):63-8.

Tabela 1. Resumo do espectro anti-bacteriano das drogas antimicrobianas mais frequentemente utilizadas

\begin{tabular}{|c|c|c|}
\hline Classe ou Grupo & Droga & Espectro anti-bacteriano \\
\hline \multirow{3}{*}{ Penicilinas } & Ampicilina, amoxicilina & Estreptococos \\
\hline & Oxacilina & Estafilococos, estreptococos \\
\hline & Piperacilina & Estreptococos, enterobactérias e Pseudomonas aeruginosa \\
\hline \multirow{5}{*}{ Cefalosporinas } & $1^{\text {a }}$ geração & Estreptococos, estafilococos, enterococos \\
\hline & $2^{\mathrm{a}}$ geração & $\begin{array}{l}\text { Cefuroxime: mesma atividade que } 1^{\text {a }} \text { geração acrescida de Haemo- } \\
\text { philus influenzae. } \\
\text { Cefoxitina: enterobactérias e anaeróbios }\end{array}$ \\
\hline & $3^{\mathrm{a}}$ geração & Enterobactérias e estreptococos \\
\hline & $3^{\text {a }}$ geração anti-pseudomonas & Enterobactérias e Pseudomoans aeruginosa \\
\hline & $4^{\mathrm{a}}$ geração & $\begin{array}{l}\text { Atividade semelhante à } 1^{\mathrm{a}} \text { geração combinada à } 3^{\mathrm{a}} \text { geração } \\
\text { anti-pseudomonas }\end{array}$ \\
\hline \multirow[b]{2}{*}{ Carbapenens } & Ertapenem & Esterobactérias, estreptococos, estafilococos, anaeróbios \\
\hline & Imipenem, meropenem & $\begin{array}{l}\text { Mesma atividade que ertapenem acrescida de Pseudomonas } \\
\text { aeruginosa e Acinetobacter spp. }\end{array}$ \\
\hline \multirow{3}{*}{$\begin{array}{l}\text { Combinação com } \\
\text { inibidores de } \\
\text { beta-lactamase }\end{array}$} & Amoxilina/clavulanato & Estreptococos, estafilococos e anaeróbios \\
\hline & Ampicilina /sulbactam & Estreptococos, estafilococos, anaeróbios e Acinetobacter spp. \\
\hline & Piperacilina/tazobactam & $\begin{array}{l}\text { Estreptococos, estafilococos, enterococos, enterobactérias, } \\
\text { Pseudomonas aeruginosa e anaeróbios }\end{array}$ \\
\hline \multirow{2}{*}{ Aminoglicosídeos } & Gentamicina & Enterobactérias \\
\hline & Amicacina & Enterobactérias e Pseudomonas aeruginosa \\
\hline \multirow{2}{*}{ Macrolídeos } & $\begin{array}{l}\text { Eritromicina, Roxitromicina, } \\
\text { claritromicina }\end{array}$ & $\begin{array}{l}\text { Estreptococos, Mycoplasma pneumoniae, Chlamidophila } \\
\text { pneumoniae, Chlamydia trachomatis, Legionella spp. }\end{array}$ \\
\hline & Azitromicina & $\begin{array}{l}\text { Semelhante aos outros macrolídeos acrescido de Haemophilus } \\
\text { influenzae }\end{array}$ \\
\hline \multirow{4}{*}{ Quinolonas } & Ac. nalidíxico & Escherichia coli (apenas cistite) \\
\hline & Norfloxacina & Escherichia coli (apenas cistite) \\
\hline & Ciprofloxacina & Enterobactérias, Pseudomonas aeruginosa, estafilococos \\
\hline & Quinolonas respiratórias & Enterobactérias, estreptococos, estafilococos \\
\hline \multirow{3}{*}{$\begin{array}{l}\text { Drogas com ação } \\
\text { anti-anaeróbios }\end{array}$} & Clindamicina & Anaeróbios, estreptococos, estafilococos \\
\hline & Metronidazol & Anaeróbios \\
\hline & Cloranfenicol & $\begin{array}{l}\text { Anaeróbios, estreptococos, Escherichia coli e algumas outras } \\
\text { enterobactérias }\end{array}$ \\
\hline Glicopeptídeos & Vancomicina, teicoplanina & Estafilococos resistentes a beta-lactâmicos \\
\hline Sulfas & Sulfametoxazol/trimetoprim & Estafilococos, Escherichia coli e algumas outras enterobactérias \\
\hline Lipopeptídeo & Daptomicina & Estreptococos, estafilococos, enterococos \\
\hline Oxazolidinona & Linezolida & Estreptococos, estafilococos, enterococos \\
\hline Polimixinas & Polimixina B, colistina & $\begin{array}{l}\text { Enterobactérias, Pseudomonas aeruginosa, Acinetobacter spp. } \\
\text { (utiliza-se principalmente contra bactérias multirresistentes) }\end{array}$ \\
\hline
\end{tabular}




\section{Quando começar um tratamento antibiótico?}

À suspeita de infecção devemos tentar identificar o foco. Somente conhecendo o foco da infecção poderemos avaliar o tipo de culturas a serem colhidas, esquemas empíricos de tratamento e poderemos acompanhar a resposta ao tratamento instituído. Em pacientes ambulatoriais, infecções frequentes são: de vias aéreas superiores (incluindo sinusite, otite, faringite); pele e partes moles; infecções urinárias (cistite e pielonefrite) e pneumonia. A história clínica e exame físico nos auxiliam neste sentido. A seguir, devem ser colhidos exames auxiliares: hemograma, urina, ou métodos de imagem e não se deve esquecer de colher culturas. Nos casos bem definidos, por exemplo infecções urinárias ou pneumonias, pode-se iniciar tratamento antes de ter em mãos os resultados, baseando-se nos agentes etiológicos que mais frequentemente causam essas infecções. Quando os resultados de culturas estiverem prontos o tratamento pode ser reavaliado e ajustado.

Em pacientes internados, porém não-críticos, recomenda-se confirmar o foco infeccioso avaliando os resultados de exames e culturas antes de iniciar antibioticoterapia.

Em pacientes críticos (em unidade de terapia intensiva) pode-se introduzir antibióticos uma vez que haja forte suspeita de foco infeccioso e tenham sido colhidas culturas, em especial hemoculturas (pelo menos dois pares).

É importante lembrar que os resultados de culturas e sua sensibilidade são afetados pelo uso de antibióticos e é preferível colhê-las antes da introdução destas drogas, ou da mudança de esquema.

Como situação ideal devemos:

a. conhecer o foco de infecção;

b. ter o isolamento do agente etiológico;

c. utilizar o antibiótico dirigido ao agente, com menor espectro de ação contra outros agentes infecciosos;

d. tratar pelo menor tempo possível, sem comprometer a eficácia do tratamento.

\section{Qual é a duração ideal de um tratamento antibiótico?}

Depende do foco infeccioso em tratamento. Geralmente a duração deve variar de 7 a 14 dias. Somente em situações especiais este tempo é prolongado: endocardite bacteriana (4 a 6 semanas); abscessos (duração indeterminada, enquanto houver a coleção); osteomielite (3 ou mais semanas). Lembramos que, em algumas situações, o uso de antibiótico é ineficaz, pois existe a necessidade de drenagem ou limpeza cirúrgica (ex. abscessos, grande quantidade de material necrótico) para uma boa resolução da infecção. Como regra, a melhor duração é o menor tempo (em geral no intervalo de 7 a 14 dias) que não comprometa a eficácia do tratamento. Esta decisão depende de avaliação clínica, das doenças de base do paciente e do tempo de resposta como desaparecimento de febre, melhora de leucocitose, etc.

\section{Uma vez iniciado um esquema antibiótico ele pode ser alterado ou suspenso antes do seu final?}

Sim. Muitas vezes começamos o uso de antibióticos antes de ter em mãos os resultados de culturas. Frente ao resultado, podemos alterar o esquema para um de menor custo, de espectro mais limitado e dirigido, ou mais fácil de administrar. Quando se isolar um agente, de cultura de material significativo, que não está coberto pelo esquema em uso, este deve ser modificado para a cobertura apenas dos agentes isolados. Outras vezes, em pacientes graves, iniciamos esquema antibiótico empiricamente e depois verificamos que a causa do agravo é não-infecciosa: assim devemos suspender o antibiótico.

\section{O que são: infecção, colonização e contaminação?}

Infecção é o fenômeno causado pela replicação de um microorganismo nos tecidos de um hospedeiro, levando a uma resposta imunológica deste. A infecção pode ou não provocar doença, com manifestações clínicas. Colonização é a presença de microorganismos com multiplicação em um hospedeiro sem manifestações clínicas ou resposta imunológica. O termo contaminação se refere à presença de microorganismos em uma cultura sem que estes representem colonização ou infecção. Também é a presença de microorganismos em objetos inanimados.

\section{Os resultados de culturas devem ser valorizados sempre?}

Devemos considerar como agentes etiológicos bem determinados de uma infecção apenas aqueles isolados em culturas de material habitualmente estéril (ex. sangue, líquor, líquidos cavitários, líquidos colhidos de bolhas íntegras ou cápsula articular, ou material profundo colhido durante o ato operatório). Mesmo nestes casos pode haver contaminação de amostra se não houver coleta adequada (ex. contaminação na coleta de hemocultura por microbiota de pele) ou armazenamento ou encaminhamento inadequado ao laboratório. A urina, mesmo quando colhida adequadamente, pode ser positiva na ausência de infecção, por contaminação do trato urinário baixo. Por isso é feita a cultura quantitativa. Quando houver 3 ou mais agentes isolados em urina ou lavado broncoalveolar, mesmo em contagens significativas, considere fortemente a possibilidade de contaminação do material.

Materiais colhidos de locais do corpo habitualmente colonizados por microbiota microbiana (como cavidade oral, vias respiratórias ou trato digestivo) não tem valor como diagnóstico etiológico de infecção. O mesmo ocorre 
quando se colhe material de lesões abertas de pele, expostas ao ambiente, como feridas, escaras, bolhas já rompidas, etc. $\mathrm{O}$ isolamento de anaeróbios pode ser difícil e pode resultar negativo sem que isto signifique ausência de infecção por anaeróbio. Deve-se sempre suspeitar de anaeróbios em infecções de trato genital feminino, infecções associadas à manipulação intestinal e infecções em pé diabético.

\section{Frente à aparente falha de tratamento com uma droga adequada a uma bactéria isolada em cultura, qual deve ser a conduta?}

Várias podem ser as causas de falha de tratamento antibiótico:

a.manutenção do foco infeccioso fechado cuja abordagem deve ser cirúrgica (ex. abscesso);

b. dose inadequada de antibiótico;

c.resistência do agente etiológico ao esquema antibiótico usado;

d. outro agente etiológico associado, que não foi devidamente tratado. investigada.

Cada uma das hipóteses acima deve ser cogitada e

\section{A persistência de febre durante o tratamento adequa- do de infecção deve ser considerada falha?}

Alguns agentes como Staphylococcus aureus podem levar a febre prolongada por dias ou até semanas após o início do tratamento apropriado, porém, nestes casos, a resposta clínica do paciente é evidente com melhora do estado geral e do foco de infecção. Para os outros agentes, em sua maioria, ocorre uma resposta com desaparecimento de febre em até 3 ou 4 dias de tratamento. Quando isto não ocorre, deve-se suspeitar de outra causa, não-infecciosa de febre, ou de uma complicação como abscesso ou coleção não diagnosticada. Se o agente etiológico da infecção sob tratamento não tiver sido isolado, deve-se considerar a possibilidade de a cobertura antibiótica ter sido inadequada.

\section{Quando deve-se utilizar a via endovenosa?}

Em geral, com poucas exceções (como no caso do metronidazol), o antibiótico por via endovenosa atinge concentrações séricas e teciduais mais elevadas que a forma oral. Assim, deve-se utilizar a via endovenosa em casos de infecções graves. Também utiliza-se esta via quando o paciente apresentar problemas de absorção do trato gastrointestinal, como por exemplo, íleo paralítico. Lembrar que o acesso vascular oferece um aumento de risco de infecção hospitalar e deve ser abandonado assim que as condições clínicas do paciente o permitirem.

\section{Quando um paciente está em tratamento antibiótico parenteral e passará para oral, é necessário utilizar}

\section{a mesma droga ou classe de droga?}

Atualmente acredita-se que, mantendo o espectro de ação, a classe de droga não precisa ser mantida durante todo o tratamento. Algumas vezes a droga utilizada por via endovenosa não é disponível na forma oral e é trocada por outra. Nestes casos a contagem do tempo de tratamento é continuada a partir do início do tratamento (endovenoso).

\section{Podem-se utilizar vias alternativas de administração de antibióticos?}

Há descrito o uso de antimicrobianos por via intratecal assim como irrigação vesical. Não devem ser utilizados a não ser em casos de absoluta exceção. A irrigação ou instilação em cavidades, como peritônio, pleura ou sítio cirúrgico, não deve ser usada.

\section{Como deve ser encarada a associação de antibióticos?}

Pode-se associar antibióticos para a ampliação do espectro de ação. Por exemplo, em infecções ginecológicas usa-se mais de um antibiótico para atingir diferentes agentes de uma infecção mista: anaeróbios e bacilos gram-negativos.

A associação para a obtenção de efeito sinérgico contra um determinado agente infeccioso, é considerada controversa e não deve ser usada rotineiramente, exceto no caso de Enterococcus spp. em que ampicilina (ou penicilina) e aminoglicosídeo (gentamicina ou estreptomicina) têm efeito sinérgico comprovado.

Como medida de prevenção da emergência de resistência durante o tratamento, a associação de antibióticos é ineficaz.

\section{O que é profilaxia antimicrobiana?}

É o uso de antimicrobianos para prevenir o surgimento de infecção em um paciente, durante uma situação de risco. Pacientes com infecção ou com forte suspeita de infecção não devem receber profilaxia e sim tratamento. Exemplos de profilaxia antimicrobiana: o uso de antibióticos em pacientes portadores de prótese valvar em situações de risco para bacteremia como extrações dentárias; ou o uso de antimicrobiano durante ato operatório com alto risco para infecção pós-cirúrgica.

\section{Como se faz a profilaxia antimicrobiana em cirurgia?}

A profilaxia antibiótica não é indicada em todas as cirurgias. Naquelas cirurgias em que há indicação de profilaxia ela deve ser iniciada na indução anestésica, devem ser administradas doses suplementares durante o 
ato operatório se este tiver duração prolongada, e deve ser suspensa, no máximo, com 24 horas de uso. A profilaxia deve ser sempre por via endovenosa. Não se justifica prolongar o tempo de profilaxia pela manutenção de fatores de risco como drenos ou cateteres. Também não se deve prolongar o tempo de profilaxia devido ao mau estado geral

\section{REFERÊNCIAS}

1. Fleming A. On the antibacterial action of cultures of a penicillium, with special reference to their use in the isolation of B. influenzæ. Br J Exp Pathol. 1929;10(3):226-236. doi: 10.1097/00000441-193009000-00056.

2. Chain E, Florey HW, Gardner AD, Heatley NG, Jennings MA, Orr-Ewing J, Sanders AG. Penicillin as a chemotherapeutic agent. Lancet. 1940;236(6104):226-8. doi: 10.1016/S01406736(01)08728-1. do paciente. Para a profilaxia em cirurgia utilizam-se doses altas e intervalos curtos de administração. Como exemplo, citamos a cefazolina $2 \mathrm{~g}$ a cada 4 horas, e a cefoxitina $2 \mathrm{~g}$ a cada 4 horas por via endovenosa, que são doses no limite superior do recomendado.

3. Abraham EP, Gardner AD, Chain E, Heatley NG, Fletcher CM, Jennings MA, Florey HW. Further observations on penicillin. Lancet. 1941;238(6155):177-89. doi: 10.1016/ S0140-6736(00)72122-2.

4. Levin AS, Souza Dias MBG, editores. Antimicrobianos: um guia de consulta rápida. São Paulo: Atheneu; 2006. Cap.5, p.61-6: Perguntas mais frequentes. 